\title{
Impact of A Mobile App For Antibiotic Stewardship on The Incidence of Nosocomial Infections With Multidrug Resistant Micro Organisms
}

\author{
Paulo Castañeda-Méndez*1, Marco Villanueva-Reza², Luis Enrique Soto Ramírez ${ }^{3}$, \\ Daniel Antonio Aguilar-Zapata ${ }^{3}$, María Lorena Cabrera-Ruiz ${ }^{3}$, Javier Reyes-Mar ${ }^{3}$, \\ Israel Rojas-de Ita², Andrea Priscila Hernández-Pérez² , Esperanza Aleman-Aguilar ${ }^{4}$ \\ and Lorena Lanz-Zubiria ${ }^{5}$
}

${ }^{1}$ Internal Medicine, Infectology Máster in infection control, Hospitalary Epidemiologic Vigilance Unit, Antibiotic Stewardship Program Coordinator, Clinical Foundation Medica Sur, Mexico

${ }^{2}$ Internal Medicine, Clinical Foundation Medica Sur, Mexico

${ }^{3}$ Internal Medicine, Infectology, Hospitalary Epidemiologic Vigilance Unit Chief, Clinical Foundation Medica Sur, Mexico

${ }^{4}$ Informatic degree, Hospitalary Epidemiologic Vigilance Unit. Clinical Foundation Medica Sur, Mexico

${ }^{5}$ General physician, Clinical Foundation Medica Sur, Mexico

*Corresponding author: Paulo Castañeda-Méndez, Internal Medicine, Infectology, Master in infection control, Hospitalary

Epidemiologic Vigilance Unit, Antibiotic Stewardship Program Coordinator, Clinical Foundation Medica Sur, Mexico

\section{ARTICLE INFO}

Received: 幽 February 25, 2020

Published: 慧 March 05, 2020

Citation: P Castañeda-Méndez, M VillanuevaReza, Luis E S Ramírez, D A Aguilar-Zapata, María L Cabrera-Ruiz, et al., Impact of A Mobile App For Antibiotic Stewardship on The Incidence of Nosocomial Infections With Multidrug Resistant Micro Organisms. Biomed J Sci \& Tech Res 26(2)-2020. BJSTR. MS.ID.004334.

Keywords: Mobile App; Mexico; Antimicrobial Stewardship Program; Multiple-Drug Resistance

\section{ABSTRACT}

Objectives: to determine the impact of a guideline for empiric antimicrobial treatment based on local data of microorganism resistance delivered via mobile app as a strategy of an antibiotic stewardship program on the incidence of nosocomial infections and isolation of multidrug resistant microorganisms.

Methods: retrospective, unicentric, observational study developed in a private hospital in Mexico City. We compared the incidence of nosocomial infections and isolation of multidrug resistant (MDR) microorganisms in 2013, year in which the local guidelines for empiric antimicrobial treatment were implemeted as a strategy of the antibiotic stewardship program, with the incidence of 2018. We also determined the annual percentage of adherence to the guidelines.

Results: we observed progresive increase in guideline adherence and a progresive decrease in the incidence of nosocomial infections as well as the proportion of MDR microorganisms isolates.

Conclusion: similar to previous reports in other countries, the instauration of antibiotic stewardship programs contributed to the decrease in nosocomial infections and MDR bacteria isolates in a private hospital in Mexico City.

Abbreviations: MDR: Multi-Drug Resistant, ESBL: Extended Spectrum Beta-Lactamase, VRE: Vancomycin Resistant Enterococcus, NNIS: National Nosocomial Infections Surveillance, ESBL: Extended Spectrum Beta-Lactamase, BSI: Blood Stream Infections, UTI: Urinary Tract Infection 


\section{Introduction}

Multi-Drug Resistant (MDR) microorganisms are defined as microorganisms, predominantly bacteria, resistant to one or more class of antimicrobial agents. Bacteria as Methicillin Resistant Staphylococcus Aureus (MRSA), high or intermediate level vancomycin resistant Staphylococcus aureus, Vancomycin Resistant Enterococcus (VRE), Extended Spectrum Beta-Lactamase (ESBL) producing enterobacteriaceae, Acinetobacter baumannii resistant to all antimicrobial agents, carbapenemic resistant Pseudomonas aeruginosa or bacteria inherently resistant to broad spectrum antimicrobial agents, such as Stenotrophomonas maltophilia, Burkholderia cepacia and Ralstonia pickettii. Prevalence of MDR microorganisms is variable, depending on timing, geography and site of health care [1]. Infections associated with MDR microorganisms have increased in the last decades. For example, in healthcare facilities that report to the National Nosocomial Infections Surveillance (NNIS) System network in the United States of America, the percentage of Staphylococcus aureus isolates that were methicillin resistant increased from $36 \%$ in 1992 to $64 \%$ in 2003 [2].

Similarly, in the intensive care units of the same network, there was an increase of isolates of Acinetobacter baumannii from $4 \%$ in 1986 to $7 \%$ in 2003, with a significant increase in resistance profiles, as well as an increase of isolates of imipenem and ceftazidime resistant Pseudomonas aeruginosa and ESBL Escherichia coli [3]. In Mexico, the same trend towards increase in bacterial resistance has been reported, for example, one study group reported that Acinetobacter baumannii meropenem-sensitive decreased from $92 \%$ in 1999 to $12 \%$ in 2012 [4]. According to data from the Hospitalary Network of Epidemiological Vigilance (RHOVE) in 2015, there was an increase in isolates of ESBL Escherichia coli, Klebsiella pneumoniae y Enterobacter cloacae, as well as imipenem and quinolone resistant Pseudomonas aeruginosa, Clostridioides difficile and Acinetobacter baumannii. The lethality rate increased from $4.8 \%$ deaths in 2014 to $5.8 \%$ deaths in 2015 [5].

Rationale for rise in microorganism resistance is variable, depending on geographical situation and specific agents. However, the selective pressure secondary to indiscriminate antibiotic use that, in Mexico, could be purchased without medical prescription until 2010, inadecuate infection control practices, increase in the amount of vulnerable patients associated to longer survival in chronic disease and disease associated with immunosupression, antibiotic use in agriculture and farming industry for human consumption and globalization are some factors associated with increase in bacterial resistance [6]. Infections with multi-drugresistant bacteria are associated with increase in hospitalization lenght, need of surgery to achieve infection control, delay in starting adecuate antimicrobial therapy, the need for antimicrobial agents with greater toxicity and rise in moribidity and mortality, that lead to higher health expenditure. In the United States of America the estimated total cost of antimicrobial resistance is 30 billion dollars a year [7].

In Spain, a retrospective study reported a higher all-cause mortality rate in individuals with nosocomial infections caused by MDR bacteria (OR 2.17) and a higher ammount of emergency room visits for patients infected by MRSA and resistant strains of Escherichia coli; there was no rise in time of hospital stay, need for admission in general ward or intensive care unit, need for surgery or diagnostic tests, however, individuals infected with more than one multidrug-resistant microorganism and the ones with two or more episodes of infection during hospital stay where excluded [8]. Additionally, in low income countries, the access to certain antimicrobial drugs is limited by availability and cost. Antibiotic stewardship programs intent to reduce incidence of infections caused by MDR microorganism in healthcare facilities. The goals are antimicrobial drug use optimization, to reduce adverse effects and, ultimately, decrease mortality. Implementation of these programs proved to be associated with a decrease in isolates of resistant bacteria with adequeate adherence to recommendations.

A study developed in Andalucia, Spain showed a 10\% reduction in imipenem resistant Pseudomonas aeruginosa and a 13\% decrease in ESBL Klebsiella pneumoniae, with a healthcare expenditure saving of 30,000 euro annually [9]. Other studies have similar findings, with decrease in incidence of MDR bacteria, Clostridioides difficile and also a decrease in antimicrobial defined daily dose [10-15]. The objective of this study was to determine the impact of a guidelines for empiric antimicrobial treatment delivered via mobile app, as a strategy of an antimicrobial stewardship program introduced in 2013 in the incidence of nosocomial infections and isolation of MDR microorganisms in a tertiary referral hospital in Mexico city.

\section{Materials and Methods}

Retrospective, observational, unicentric study developed in Medica Sur, a tertiary referral private hospital in Mexico city. All nosocomial infections from january 1st 2013 to december 31th 2018 registered by the epidemiological vigilance unit. MDR nosocomial infections were defined as hospital-acquired infections caused by ESBL Escherichia coli, ESBL Klebsiella spp, Carbapenemic Resistant Enterobacteriaceae (CRE), carbapenemic resistant Pseudomonas spp, Vancomycin Resistant Enterococcus Spp (VRE) or Methicillin-Resistant Staphylococcus Aureus (MRSA). We used definitions of Ventilator Associated Pneumonia (VAP), HospitalAcquired Pneumonia (HAP), Urinary Tract Infection (UTI), Blood Stream Infections (BSI) and Soft Tissue Infection (STI) published by the World Health Organisation (WHO). Reports by year, infection site and MDR microorganism were obtained. 
Local guidelines for empirical antimicrobial treatment are availible as a mobile app in IOS and Android platforms since 2013 and contain recomendations for empiric antimicrobial treatment based on local bacterial resistance records. These guidelines include recomendations for the most common infectious disease in our insitution see (Table 1). The app, called PURA MS, was developed by the Epidemiological Vigilance Unit staff of our hospital and it is availible for all healthcare professionals authorised to prescribe antibiotics in the hospital and who are trained twice a year in the use PURA MS app; the contents are updated at least once a year. Adherence to local guidelines for empiric antimicrobial treatment are reported in percentage of adequate treatment of the total of empirical treatment registries. We assess 70 cases selected randomly every month. We compared the percentage of annual adherence to local guidelines for empiric antimicrobial treatment availible in the PURA MS mobile app with the annual percentage of nosocomial infections caused by MDR bacteria.

Table 1: List of infections included in local guidelines of empiric antimicrobial treatment PURA MS.

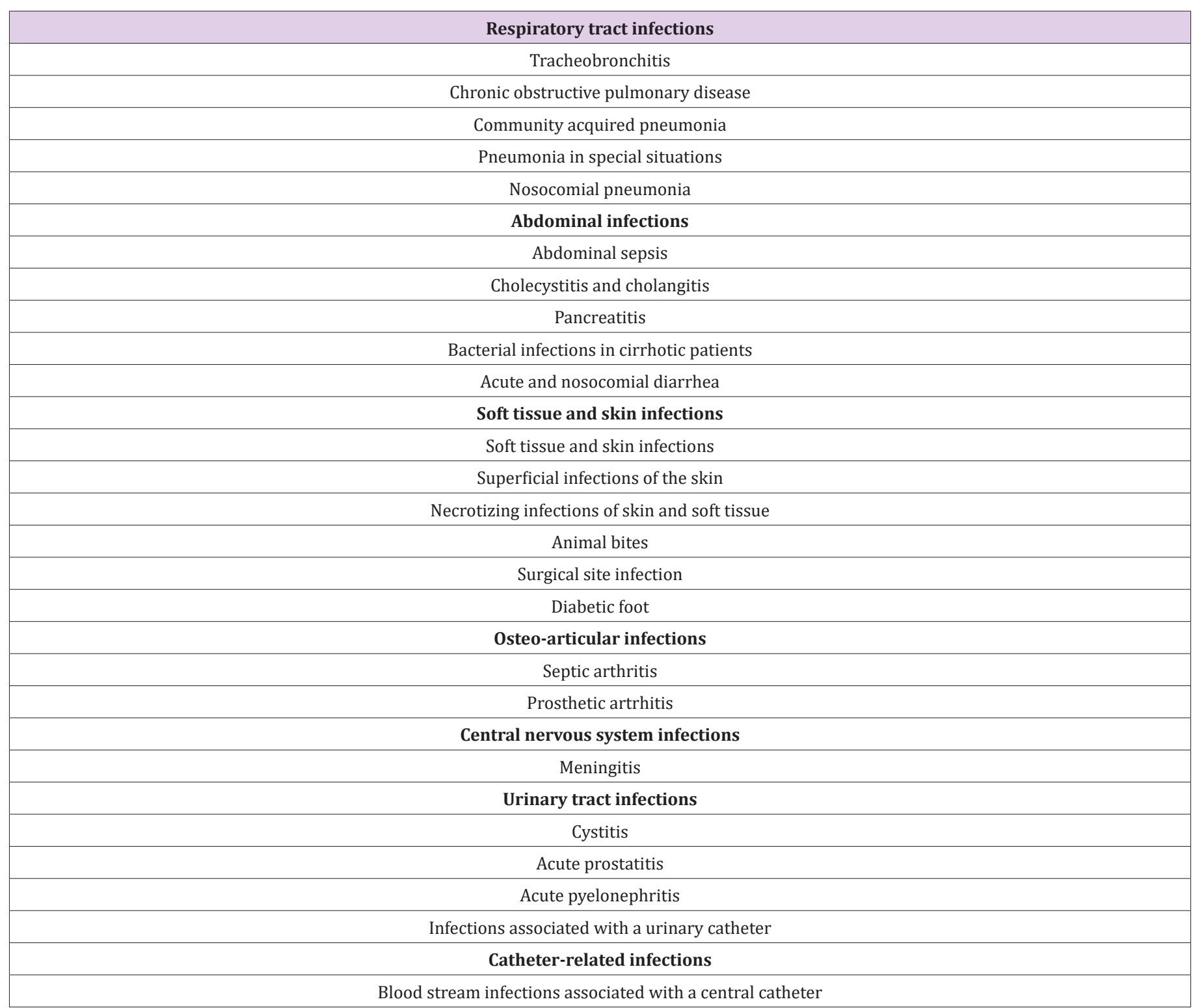

\section{Results}

We assessed 6 years, from 2013 to 2018. Avarage annual discharge rate was 13824 to 15754 patients/year. Initial adherence to local guidelines for empiric antimicrobial treatment was low (42.2\%) in 2013 and progresively increased annualy until $79.8 \%$ adherence in 2018, attributed to a systematic training of healthcare professionals authorised to prescribe antimicrobials in the hospital and a handier access to guidelines. As the adherence to local guidelines increased, the percentage of nosocomial acquired infections caused by MDR bacteria decreased from 25\% in 2013 to $15 \%$ in 2018 (Table 2) associated with an increase in adherence to local empiric antimicrobial treatment guidelines (Figure 1). During the study period, we observed a decrease in the incidence of MDR bacteria strains causing nosocomial infections in 2018 compared to 2013. Nosocomial infections caused by ESBL Escherichia coli 
decreased by $10.7 \%$, ESBL Klebsiella spp by $19 \%$, carbapenem resistant Pseudomonas aeruginosa by $29.5 \%$, methicilin resistant Staphylococcus aureus decreased from $55.6 \%$ to $0 \%$ in the same period of time (Table 3). By type of nosocomial infection caused by MDR bacteria, hospital acquired pneumonia decreased by $20 \%$, surgical site infection by $7.9 \%$, blood stream infection diminished from $28.6 \%$ in 2013 to $0 \%$ in 2018 (Table 4).

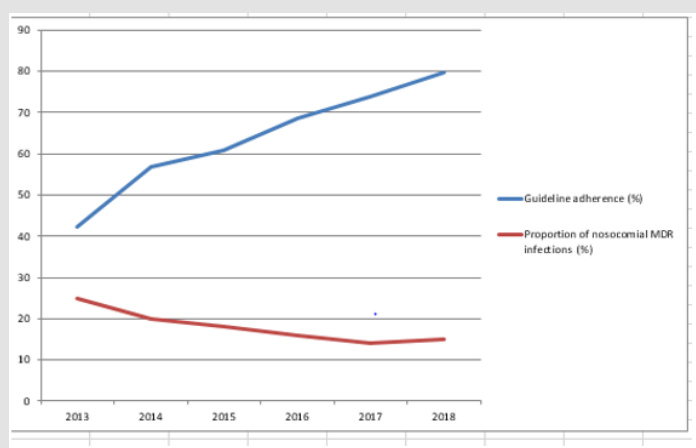

Figure 1: Annual adherence to local guidelines and percentage of nosocomial infections caused by MDR microorganisms.

Table 2: Annual percentace of nosocomial MDR microorganism infections from 2013 to 2018.

\begin{tabular}{|c|c|c|c|c|c|c|c|c|}
\hline & $\begin{array}{c}\text { Annual } \\
\text { discharge }\end{array}$ & $\begin{array}{c}\text { Guideline } \\
\text { adherence } \\
(\%)\end{array}$ & $\begin{array}{c}\text { Nosocomial } \\
\text { infections (n) }\end{array}$ & $\begin{array}{c}\text { Positive } \\
\text { cultures (n) }\end{array}$ & $\begin{array}{c}\text { Positive } \\
\text { cultures (\%) }\end{array}$ & $\begin{array}{c}\text { MDR isolates } \\
\text { (n) }\end{array}$ & $\begin{array}{c}\text { Proportion of } \\
\text { nosocomial } \\
\text { MDR } \\
\text { infections (\%) }\end{array}$ & $\begin{array}{c}\text { Proportion of } \\
\text { MDR bacteria } \\
\text { in positive } \\
\text { cultures (\%) }\end{array}$ \\
\hline 2013 & 15754 & 42.2 & 239 & 165 & 69 & 61 & 25 & 36 \\
\hline 2014 & 14747 & 56.7 & 197 & 138 & 70 & 40 & 20 & 28 \\
\hline 2015 & 14043 & 60.7 & 187 & 134 & 71 & 35 & 18 & 26 \\
\hline 2016 & 13978 & 68.7 & 193 & 142 & 73 & 32 & 16 & 22 \\
\hline 2017 & 13824 & 73.7 & 190 & 148 & 77 & 28 & 14 & 18 \\
\hline 2018 & 14017 & 79.8 & 152 & 124 & 81 & 23 & 15 & 18 \\
\hline TOTAL & 86363 & 63.3 & 1158 & 851 & 73 & 219 & 18 & 24.6 \\
\hline
\end{tabular}

Table 3: Microorganisms and proportion of MDR status in nosocomial infections by year (2013-2018).

\begin{tabular}{|c|c|c|c|c|c|c|c|c|}
\hline & & 2013 & 2014 & 2015 & 2016 & 2017 & 2018 & TOTAL \\
\hline E. coli & Total & 53 & 33 & 24 & 35 & 35 & 29 & 209 \\
\hline \multirow[t]{2}{*}{ ESBL } & ESBL & 29 & 23 & 17 & 20 & 14 & 13 & 116 \\
\hline & $\%$ & 54.7 & 69.7 & 70 & 57 & 46 & 44 & 55 \\
\hline Klebsiella spb. & Total & 21 & 11 & 5 & 8 & 8 & 13 & 66 \\
\hline \multirow[t]{2}{*}{ ESBL } & ESBL & 12 & 3 & 3 & 4 & 6 & 5 & 33 \\
\hline & $\%$ & 57 & 27 & 60 & 50 & 37.5 & 38 & 50 \\
\hline Enterobacteriaceae & Total & 74 & 44 & 29 & 0 & 2 & 29 & 178 \\
\hline \multirow[t]{2}{*}{ CRE } & CRE & 0 & 0 & 1 & 0 & 2 & 1 & 4 \\
\hline & $\%$ & 0 & 0 & 3.4 & 0 & 4.3 & 3.4 & 2 \\
\hline Pseudomonas & Total & 13 & 19 & 20 & 13 & 13 & 12 & 90 \\
\hline \multirow[t]{2}{*}{ MDR } & MDR & 3 & 3 & 1 & 0 & 0 & 1 & 8 \\
\hline & $\%$ & 23.1 & 15.8 & 5 & 0 & 0 & 8.2 & 8 \\
\hline Pseudomonas & Total & 13 & 19 & 20 & 13 & 13 & 12 & 90 \\
\hline \multirow[t]{2}{*}{ CRE } & $\begin{array}{c}\text { Carbapenemic } \\
\text { resistant }\end{array}$ & 6 & 4 & 10 & 5 & 5 & 2 & 32 \\
\hline & $\%$ & 46.2 & 21.1 & 50 & 38 & 38 & 16.7 & 35 \\
\hline Staphylococcus aureus & Total & 9 & 7 & 10 & 5 & 5 & 12 & 48 \\
\hline MRSA & MRSA & 5 & 2 & 0 & 2 & 1 & 0 & 10 \\
\hline
\end{tabular}




\begin{tabular}{|c|c|c|c|c|c|c|c|c|}
\hline & $\%$ & 55.6 & 28.6 & 0 & 40 & 16 & 0 \\
\hline Enterococcus & Total & 0 & 0 & 9 & 15 & 15 & 10 \\
\hline VRE & VRE & 0 & 0 & 1 & 0 & 0 & 49 \\
\hline & $\%$ & 0 & 0 & 11 & 0 & 0 & 1 \\
\hline
\end{tabular}

Table 4: Type of nosocomial infection by year (2013-2018).

\begin{tabular}{|c|c|c|c|c|c|c|c|c|}
\hline 2013 & 2014 & 2015 & 2016 & 2017 & 2018 & TOTAL & & \\
\hline \multirow{3}{*}{$\begin{array}{l}\text { Ventilator } \\
\text { associated } \\
\text { pneumonia }\end{array}$} & Total & 12 & 12 & 4 & 3 & 4 & 5 & 40 \\
\hline & MDR & 5 & 6 & 2 & 0 & 1 & 1 & 15 \\
\hline & $\%$ & 41 & 50 & 50 & 0 & 25 & 20 & 37 \\
\hline \multirow{3}{*}{$\begin{array}{c}\text { Hospital } \\
\text { acquired } \\
\text { pneumonia }\end{array}$} & Total & 58 & 60 & 36 & 44 & 43 & 24 & 265 \\
\hline & MDR & 5 & 5 & 2 & 1 & 1 & 3 & 17 \\
\hline & $\%$ & 8.6 & 8.3 & 5.6 & 2.3 & 2.3 & 12.5 & 6 \\
\hline \multirow[t]{3}{*}{$\begin{array}{l}\text { Urinary tract } \\
\text { infection }\end{array}$} & Total & 39 & 29 & 19 & 32 & 23 & 17 & 159 \\
\hline & MDR & 17 & 13 & 8 & 11 & 8 & 7 & 64 \\
\hline & $\%$ & 43.6 & 44.8 & 42.1 & 34.4 & 34 & 41.2 & 40 \\
\hline \multirow[t]{3}{*}{$\begin{array}{l}\text { Surgical site } \\
\text { infection }\end{array}$} & Total & 76 & 39 & 54 & 57 & 47 & 41 & 314 \\
\hline & MDR & 13 & 12 & 19 & 11 & 7 & 7 & 69 \\
\hline & $\%$ & 25 & 30.6 & 35 & 19.3 & 14.9 & 17.1 & 21 \\
\hline \multirow[t]{3}{*}{$\begin{array}{l}\text { Blood stream } \\
\text { infection }\end{array}$} & Total & 7 & 5 & 17 & 5 & 6 & 7 & 47 \\
\hline & MDR & 2 & 0 & 4 & 2 & 1 & 0 & 9 \\
\hline & $\%$ & 28.6 & 0 & 11.8 & 40 & 16.7 & 0 & 19 \\
\hline
\end{tabular}

\section{Discussion}

Antimicrobial abuse generates selection pressure associated with the development of bacteria strain profiles with multiple drug resistance and some studies have shown that, in as much as $30-50 \%$ of cases, empirical antimicrobial selection of therapy, indication of treatment or duration are inadequate [14]. The development of resistant bacteria strains is already considered a public health issue that, in the United States, affects 2 million people of whom 23 000 die each year [15]. This study assessed the impact on bacterial resistance in our healthcare facility after implementation of local guidelines for empiric antimicrobial treatment developed in 2013 as a part of the antibiotic stewardship program, with a friendly interface and an handy access that guides healthcare professionals in the selection and duration of empiric antimicrobial treatment according to local bacterial resistance and international guidelines.

After the implementation of this guidelines, we observed a progresive increase in the percentage of adherence to the guidelines associated with a decrease in the percentage of nosocomial infections caused by MDR microorganisms, as well as decrease in the percentage of isolates of MDR bacteria. This results are similar to other published reports. We conclude that antibiotic stewardship programs that include use local guidelines for empiric antimicrobial treatment delivered by friendly mobile phone interfaces are effective strategies for the control of nosocomial MDR bacterial infections. This study, along with other similar studies, support the use of antimicrobial stewardship programs as a standar of hospital care to slow down this public healthcare issue.

\section{References}

1. Epidemiology | MDRO Management | Guidelines Library | Infection Control | CDC.

2. Klevens RM, Edwards JR, Tenover FC, Mc Donald LC, Horan T, et al. (2006) Changes in the Epidemiology of Methicillin-Resistant Staphylococcus aureus in Intensive Care Units in US Hospitals, 1992-2003. Clin Infect 42(3): 389-391.

3. Weinstein RA, Gaynes R, Edwards JR (2005) Overview of Nosocomial Infections Caused by Gram-Negative Bacilli. Clin Infect Dis 41(6): 848854.

4. Morfin Otero R, Alcántar-Curiel, Rocha MJ, Alpuche-Aranda CM, SantosPreciado JI, et al. (2013) Acinetobacter baumannii infections in a tertiary care Hospital in Mexico over the past 13 years. Chemotherapy 59(1): 5765.

5. (2015) Dirección General de Epidemiología S de S. Informe Annual 2015 Red Hospitalaria de Vigilancia Epidemiológica (RHOVE). Secretaria De Salud.

6. Cohen ML (2000) Changing patterns of infectious disease. Nature (6797): 762-767. 
7. Maragakis LL, Perencevich EN, Cosgrove SE (2008) Clinical and economic burden of antimicrobial resistance. Expert Rev Anti Infect Ther 6(5): 751-763.

8. Barrasa-Villar JI, Aibar-Remón C, Prieto-Andrés P, Mareca-Doñate R, Moliner-Lahoz J (2017) Impact on Morbidity, Mortality, and Length of Stay of Hospital-Acquired Infections by Resistant Microorganisms. Clin Infect Dis 65(4): 644-652.

9. Del Arco A, Tortajada B, De la Torre J, Olalla J, Prada JL, et al. (2015) The impact of an antimicrobial stewardship programme on the use of antimicrobials and the evolution of drug resistance. Eur J Clin Microbiol Infect Dis 34(2): 247-251.

10. Zou YM, Ma Y, Liu JH, Shi J, Fan T, et al. (2015) Trends and correlation of antibacterial usage and bacterial resistance: Time series analysis for antibacterial stewardship in a Chinese teaching hospital (2009-2013). Eur J Clin Microbiol Infect Dis 34(4): 795-803.

ISSN: 2574-1241

DOI: $10.26717 /$ BJSTR.2020.26.004334

Paulo Castañeda-Méndez. Biomed J Sci \& Tech Res

(C) This work is licensed under Creative

Submission Link: https://biomedres.us/submit-manuscript.php
11. Zhang ZG, Chen F, Ou Y (2017) Impact of an antimicrobial stewardship programme on antibiotic usage and resistance in a tertiary hospital in China. J Clin Pharm Ther 42(5): 579-584.

12. Dancer SJ, Kirkpatrick P, Corcoran DS, Christison F, Farmer D, et al. (2013) Approaching zero: temporal effects of a restrictive antibiotic policy on hospital-acquired Clostridium difficile, extended-spectrum $\beta$-lactamaseproducing coliforms and meticillin-resistant Staphylococcus aureus. Int J Antimicrob Agents 41(2): 137-142.

13. Hou D, Wang Q Jiang C, Tian C, Li H, et al. (2019) Evaluation of the shortterm effects of antimicrobial stewardship in the intensive care unit at a tertiary hospital in China. PLoS One 9(7): e101447.

14. (2019) The Antibiotic Resistance Crisis.

15. (2019) Biggest Threats and Data | Antibiotic/Antimicrobial Resistance | CDC.

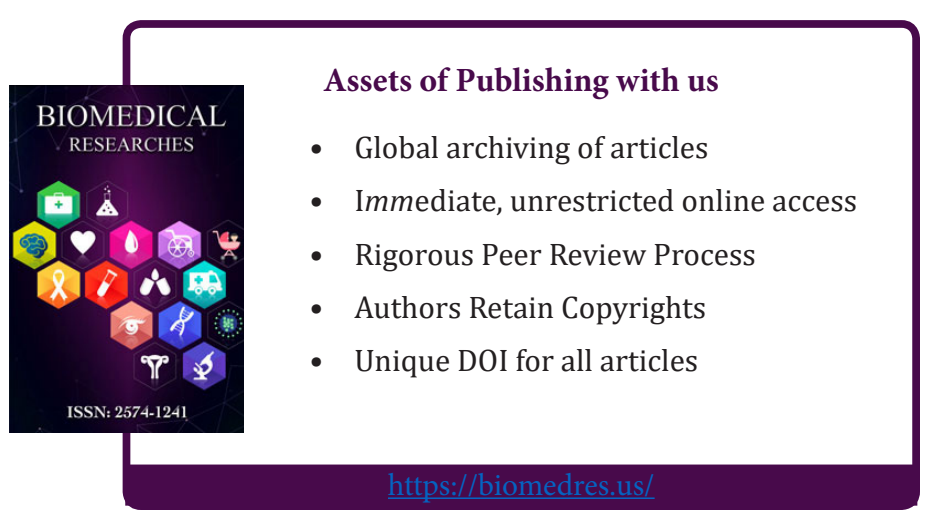

